\title{
Consórcio público e gerenciamento de resíduos sólidos: aspectos de eficiência e cooperação
}

\author{
Public consortium and solid waste management: \\ considerations of efficiency and cooperation
}

\author{
Márcia Carla Pereira Ribeiro* \\ Nahima Peron Coelho Razuk*
}

\section{Resumo}

A falta de recursos e a ausência de capacidade de planejamento são apontadas por especialistas como os principais motivos para a baixa eficiência da atuação dos municípios brasileiros na prestação dos serviços públicos relacionados ao gerenciamento de resíduos sólidos. O artigo objetiva analisar o consórcio público como instrumento de gestão associada para a prestação de serviços públicos de gerenciamento de resíduos sólidos, tendo em vista aspectos de eficiência, cooperação e sustentabilidade econômica decorrentes de sua aplicabilidade. Inicialmente, será feita uma abordagem acerca da natureza jurídica, conceitos e normas disciplinadoras dos consórcios públicos. Em seguida, serão examinados aspectos relacionados à cooperação entre os entes consorciados. Finalmente, serão apresentadas considerações sobre a Política Nacional de Saneamento Básico e a Política Nacional de Resíduos Sólidos, com enfoque nos valores de cooperação e de gestão integrada dos respectivos serviços. A partir de pesquisa bibliográfica e do método de abordagem dedutivo, foi possível concluir que a implementação de consórcio público e outros instrumentos de cooperação para o desenvolvimento de atividades relacionadas ao gerenciamento de resíduos sólidos podem resultar no aumento de eficiência e em benefícios econômicos, sendo essa forma de gestão fortemente motivada pela legislação vigente.

* Doutora em Direito das Relações Sociais. Pós-doutorado na Faculdade de Direito da Fundação Getúlio Vargas de São Paulo (2006) e na Faculdade de Direito da Universidade de Lisboa (2012). Professora Titular de Direito Societário na PUCPR e Professora Associada de Direito Comercial na UFPR. Procuradora do Estado do Paraná.

** Mestre em Direito Econômico e Socioambiental na Pontifícia Universidade Católica do Paraná (2012). Advogada sócia da banca Gonçalves, Razuk, Lemos \& Gabardo Advogados. 
Palavras-chave: Consórcio público. Gerenciamento de resíduos sólidos. Gestão associada. Eficiência. Cooperação. Política Nacional de Resíduos Sólidos.

\section{Abstract}

The lack of resources and lack of planning capacity are identified by experts as the main reasons for the low efficiency of the performance of Brazilian municipalities in the provision of public services related to solid waste management. This paper analyzes the public consortium, as a management tool associated with the provision of public solid waste management, considering the aspects of efficiency, cooperation and economic sustainability due to its applicability. Initially, an approach will be made on the legal nature, concept and standards of public consortia. Then will be examined aspects related to cooperation among the consortium entities. Finally, considerations will be presented on the National Sanitation Policy and National Solid Waste Policy, focusing on the values of cooperation and integrated management of their services. From extensive literature search and deductive method, it was concluded that the implementation of public consortium and others instruments of cooperation to develop activities related to solid waste management can result in increased efficiency and economic benefits, and management strongly motivated by legislation force.

Keywords: Public consortium. Solid waste management. Associated management. Efficiency. Cooperation. National Solid Waste Policy.

\section{Introdução}

São muitos os obstáculos e desafios para a expansão dos serviços de saneamento básico no Brasil, dentre os quais estão os serviços de limpeza urbana e manejo de resíduos sólidos. Os principais motivos do déficit de atendimento dos serviços de saneamento básico, para os quais reiteradamente apontam os especialistas, são a carência de recursos, a ineficiência no planejamento e a falta de marco regulatório o que se altera com a promulgação da Lei de Saneamento Básico (Lei $n^{\circ} 11.445$, de 5 de janeiro de 2005) e da Política Nacional de Resíduos Sólidos (Lei n 12.305, de 2 de janeiro de 2010), mesmo que ainda não estejam efetivamente implementadas. 
Especialmente em relação aos resíduos sólidos, a elevada produção pelas sociedades atuais é um problema sem precedentes que envolve aspectos culturais, como os padrões de produção e consumo, o modelo de crescimento, entre outros. Segundo o Sistema Nacional de Informações sobre Saneamento (BRASIL, 2007), os brasileiros estão concentrados nas grandes cidades e produzem uma quantidade cada vez mais volumosa de resíduos ${ }^{1}$, e grande parte não é descartada em locais adequados. A baixa eficiência da maioria dos municípios brasileiros decorre da falta de recurso e planejamento para a implementação de soluções tecnológica e ambientalmente corretas.

No que concerne às atividades relacionadas ao gerenciamento de resíduos sólidos, pode-se dizer que a Lei Federal $n^{\circ} 12.305$, de 2 de agosto de 2010, que institui seu marco regulatório, bem como a Lei Federal $n^{\circ} 11.445$, de 5 de janeiro de 2007, que estabelece as diretrizes nacionais para o saneamento básico, incentivam fortemente a formação de consórcios públicos entre os entes federativos para a prestação dos serviços essenciais, de forma compartilhada e integrada, inclusive com o direcionamento preferencial de incentivos fiscais e creditícios. As normas presentes em tais diplomas e atreladas aos valores de cooperação e de gestão integrada serão, por fim, objeto de análise.

Nesse novo cenário jurídico-normativo, a concretização da política nacional sustentável para o setor de saneamento básico brasileiro especialmente para coleta, transporte, tratamento e disposição final de resíduos - impõe novos desafios à administração pública.

E nesse contexto, o estudo examina o consórcio público como instrumento de gestão associada para a prestação de serviços públicos de gerenciamento de resíduos sólidos, tendo em vista a eficiência e a sustentabilidade econômica que pode ser conferida por ele.

\footnotetext{
Na cidade de São Paulo, por exemplo, uma pessoa chega a gerar, em média, $1 \mathrm{~kg}$ por dia de resíduo (BRASIL. MINISTÉRIO DAS CIDADES. SISTEMA NACIONAL DE INFORMAÇÕES SOBRE SANEAMENTO. Diagnóstico do manejo de resíduos sólidos urbanos - 2005 . Brasília: SNIS, 2007 p. 21-24).
} 
Inicialmente, são abordados os consórcios públicos, com apontamento da fonte constitucional (art. 241, CF/88) ${ }^{2}$, elucidação de sua natureza jurídica e seu conceito, bem como são analisadas, em linhas gerais, a norma disciplinadora dos consórcios públicos (Lei Federal $n^{\circ} 11.107$, de 6 de abril de 2005) - sem pretensão de esgotar a matéria. Em seguida, são abordados aspectos relacionados à cooperação entre os entes consorciados, a possibilidade de redução dos custos de transação e ganho de economia de escala pela utilização desse instrumento de gestão associada no desenvolvimento dos serviços públicos.

Com relação aos aspectos metodológicos, elegeu-se o método de abordagem dedutivo, e a técnica para a realização da pesquisa foi a bibliográfica, com investigação livre e exploratória sobre a temática, incluindo a análise de estudos técnicos oficialmente divulgados por órgãos públicos especializados. Observa-se que o foco do trabalho não é análise da temática à luz do direito socioambiental, em que pese a matéria tratada esteja também inserida na legislação ambiental e se conecte com princípios e valores socioambientais, e sim a identificação de possíveis benefícios de ordem econômica decorrentes da implementação de consórcios públicos gerenciadores de resíduos sólidos.

\section{Consórcio público}

Não é novidade que o sistema jurídico brasileiro contempla a possibilidade de o Estado prestar serviços públicos privativos de forma direta (mediante a criação de empresas estatais) ou indireta (por meio da outorga a particulares), na forma como prescreve o artigo 175 da Constituição Federal de 1988.

2 Desde já, é importante esclarecer que o consórcio público, objeto de análise deste artigo científico, em nada se assemelha com o consórcio de direito privado, previsto no art. $278, \S 1^{\circ}$, da Lei das S.A. Diferentemente do consórcio público, trata-se o consórcio privado de uma associação temporária entre pessoas jurídicas, não dotada de personalidade jurídica própria e, portanto, incapaz de assumir obrigações em nome próprio. 
Desse modo, o regime constitucional em vigor admite a delegação da exploração do serviço público a terceiros quando o Poder Público não tiver condições ou interesse público de executá-lo diretamente. Presume-se, para tanto, que o repasse ocorrerá nos casos concretos em que há uma decisão política em prol da melhor prestação em face do cumprimento das diretrizes fundamentais, ou seja, da prestação ótima (GABARDO, 2001), por intermédio do agente privado colaborador. No caso da prestação indireta, foi a concessão que se tornou o principal instituto jurídico utilizado no Brasil para a delegação de serviços públicos.

Quantos aos serviços públicos de saneamento básico ${ }^{3}$, a experiência administrativa brasileira apresenta poucas alterações no modelo prestacional. Alguns dos serviços de saneamento básico, como abastecimento de água potável, esgotamento sanitário, drenagem e manejo de águas pluviais, foram tradicionalmente prestados por agentes estatais. Outros, como é o caso da limpeza urbana e do manejo de resíduos sólidos, foram prestados por intermédio de delegação a agentes privados - nesses casos, elegendo-se principalmente o instituto da concessão (SOUZA, 2005). Portanto, a tendência majoritária parece ser a de ampliação da participação da iniciativa privada na prestação dos serviços de saneamento básico, em substituição às empresas estaduais (seja em regime de descentralização interna ou delegação à estatal de ente externo).

A partir da promulgação da Constituição Federal de 1988, começou-se a repensar a delimitação das competências estaduais e municipais em relação aos serviços públicos de saneamento básico, tendo em vista o conteúdo normativo do artigo $25, \S 1^{\circ}$, e do artigo 30 , inciso $\mathrm{V}^{4}$, defluindo certo conflito material de competência. Não obstante,

3 Consideram-se serviços de saneamento básico aqueles abarcados pelo artigo $3^{\circ}$ da Lei Federal $n^{\circ} 11.445 / 2007$, quais sejam: a) abastecimento de água potável; b) esgotamento sanitário; c) limpeza urbana e manejo de resíduos sólidos; d) drenagem e manejo das águas pluviais urbanas.

4 Prescreve o artigo 25, § 10: "São reservadas ao Estado as competências que não Ihe sejam vedadas por esta Constituição". Já o artigo 30, inciso V, estabelece, dentre as competências municipais, a de: "[...] organizar e prestar, diretamente ou sob regime de concessão ou permissão, os serviços públicos de interesse local, incluído o de transporte coletivo, que tem caráter essencial". 
devem prevalecer as políticas públicas de integração e planejamento capazes de atender aos objetivos comuns, com o fim de ordenar o pleno desenvolvimento das funções sociais das cidades e o bem-estar de seus habitantes. Conforme adiante examinado, a constituição de consórcios públicos entre entes federados para execução de serviços públicos se apresenta como uma alternativa para viabilizar a realização de interesses comuns e a maximização dos benefícios à população, alternativa perfeitamente aplicável aos serviços de gerenciamento de resíduos sólidos urbanos.

\subsection{Noção: base constitucional, natureza jurídica e conceito}

A possibilidade de utilização de convênios e consórcios como instrumentos jurídicos para desempenho de atividades de competência concorrente dos entes federados já encontrava amparo na interpretação do artigo 23 da Constituição Federal $^{5}$, que, no seu parágrafo único, prevê: "[a] lei federal complementar fixará normas para cooperação entre a União e os Estados, o Distrito Federal e os Municípios, tendo em vista o equilíbrio do desenvolvimento e do bem-estar em âmbito nacional."

No entanto, foi com o advento da Emenda Constitucional n 19/98, alterando a redação do artigo $241^{6}$ da Constituição Federal, que ficou definitivamente reconhecida a competência dos entes federativos em utilizar-se do regime de cooperação, via convênios ou consórcios, para levar a cabo a gestão associada de serviços públicos e os investimentos necessários à sua continuidade.

Da leitura do artigo 241 da Constituição Federal, extrai-se que o objeto do consórcio público será sempre a prestação de serviço público. Dessa forma, a aquisição de bens ou realização de obras pelo

Neste sentido, conferir Di Pietro (2006, p. 248).

"Art. 241. A União, os Estados, o Distrito Federal e os Municípios disciplinarão por meio de lei os consórcios públicos e os convênios de cooperação entre os entes federados, autorizando a gestão associada de serviços públicos, bem como a transferência total ou parcial de encargos, serviços, pessoal e bens essenciais à continuidade dos serviços transferidos." (Redação dada pela Emenda Constitucional $n^{\circ} 19$, de 1998). 
consórcio é permitida apenas quando forem instrumentais à prestação do respectivo serviço público?

Como se vê, por ocasião da sobredita Emenda, o legislador constitucional passou a reconhecer expressamente duas formas de conjugação de esforços comuns entre entes federativos e entre estes e os particulares: o convênio propriamente dito e o consórcio público.

Historicamente, a distinção entre convênios e contratos foi reconhecida pela doutrina predominante ${ }^{8}$ e pela legislação pátria, o que se depreende do artigo 48 do Decreto $n^{\circ} 93.827$, editado pela União já em 23 de dezembro de $1986,{ }^{9}$ posteriormente revogado pelo Decreto $\mathrm{n}^{\circ}$ 6.170 , de 25 de julho de $2007,{ }^{10}$ que também seguiu o entendimento da doutrina ao definir convênio nos seguintes termos:

Art. $1^{\circ}[\ldots]$

$\S 1^{\circ}$ Para os efeitos deste Decreto, considera-se:

I - convênio - acordo, ajuste ou qualquer outro instrumento que discipline a transferência de recursos financeiros de dotações consignadas nos Orçamentos Fiscal e da Seguridade Social da União e tenha como partícipe, de um lado, órgão ou entidade da administração pública federal, direta ou indireta, e, de outro lado, órgão ou entidade da administração pública estadual, distrital ou municipal, direta ou indireta, ou ainda, entidades privadas sem fins lucrativos, visando a execução de programa de governo, envolvendo a realização de projeto, atividade, serviço, aquisição de bens ou evento de interesse recíproco, em regime de mútua cooperação;

Conferir Harger (2007, p. 188).

Para tanto, conferir Meirelles (1979, p. 374).

"Art. 48. Os serviços de interesse recíproco dos órgãos e entidades de administração federal e de outras entidades públicas ou organizações particulares, poderão ser executados sob o regime de mútua cooperação, mediante convênio, acordo ou ajuste. $\S 1^{\circ}$. Quando os participantes tenham interesses diversos e opostos, isto é, quando se desejar, de um lado, o objeto do acordo ou ajuste, e de outro lado a contraprestação correspondente, ou seja, o preço, o acordo ou ajuste constitui contrato."

10 Dispõe sobre as normas relativas às transferências de recursos da União mediante convênios e contratos de repasse, e dá outras providências. 
Já o consórcio público, considerando a terminologia tradicionalmente adotada no Brasil, possui natureza jurídica de convênio, na medida em que não há interesses contrapostos ou o antagonismo de interesses que qualifica os contratos.

No entanto, mesmo perseguindo objetivos de interesse comum, o consórcio público configura, segundo concepção de Ascarelli (2000) e Justen Filho (2005) $)^{11}$, um contrato administrativo plurilateral, com efetivo cunho vinculante entre todas as partes pactuantes. Para outra parte da doutrina, como Carvalho Filho (2009), a natureza jurídica dos consórcios é a de acordo plurilateral de cooperação recíproca e, por isso, seria um negócio jurídico mais assemelhado ao convênio, empregando esse termo em sentido amplo. ${ }^{12}$

O Decreto Federal $n^{\circ}$ 6017/07, regulamentador da Lei $n^{\circ}$ 11107/05, disciplina o conceito de consórcio público no inciso I do artigo $2^{013}$. Em complementação aos termos do referido dispositivo legal, outros elementos básicos do consórcio público devem ser considerados para sua adequada conceituação: a necessidade de criação por lei ou por intermédio de autorização legislativa e o objetivo de atender, sem fins lucrativos, serviços públicos de interesse comum dos entes consorciados.

\subsection{Normas gerais sobre consórcios públicos}

Com o objetivo de regulamentar o artigo 241 da Constituição Federal, foi aprovada a Lei Federal $n^{\circ} 11.107$, de 6 abril de 2005, que normatizou de maneira minuciosa as regras gerais sobre consórcios

11 Para ele, "o contrato administrativo plurilateral ou organizacional se configura como acordo de vontades de que participa uma ou mais pessoas administrativas, por meio do qual os contratantes se obrigam reciprocamente a promover condutas ativas ou omissivas, visando a obtenção de certo resultado de interesse conjunto" (JUSTEN FILHO, 2005, p. 51).

12 Consultar Carvalho Filho (2009, p. 25 e ss).

13 "Art. 2o Para os fins deste Decreto, consideram-se: I - consórcio público: pessoa jurídica formada exclusivamente por entes da Federação, na forma da Lei $n^{0} 11.107$, de 2005, para estabelecer relações de cooperação federativa, inclusive a realização de objetivos de interesse comum, constituída como associação pública, com personalidade jurídica de direito público e natureza autárquica, ou como pessoa jurídica de direito privado sem fins econômicos" 
públicos (sendo denominada de "Lei dos Consórcios Públicos"). Ao instituto dos convênios de cooperação, a referida lei relegou nada mais que algumas passagens pontuais.

O delineamento normativo dado ao consórcio público pela Lei $n^{\circ} 11.107$, de 2005, rompeu com o tratamento tradicional até então corrente na doutrina administrativista brasileira, na medida em que o legislador passou a imprimir a natureza e disciplina jurídica de contrato administrativo ${ }^{14}$. Conforme ressaltado, antes da alteração constitucional, os consórcios eram equiparados aos convênios, no sentido de considerá-los como meros ajustes ou acordos administrativos, e não como contratos administrativos. Ao lado disso, o traço inovador atribuído aos consórcios públicos foi de que, por previsão expressa no artigo $1^{\circ}$, $\S 1^{\circ}$, da referida lei, sempre deverão adquirir personalidade jurídica. ${ }^{15}$

Logo, o consórcio público seria um ente representante dos membros consorciados dotado de personalidade jurídica, que, de acordo com os incisos do artigo $6^{\circ}$ da Lei $n^{\circ} 11107 / 05$, poderá ser "de direito público, no caso de constituir associação pública, mediante a vigência das leis de ratificação do protocolo de intenções" ou "[...] de direito privado, mediante o atendimento dos requisitos da legislação civil”.

Constituindo-se pessoa jurídica de direito público, o consórcio será, nos termos da lei, uma "associação pública" que poderá ser formada pela união de entes federativos, como pessoas jurídicas organizadas para a realização de objetivos de interesse comum. E na qualidade de associação pública, integrará a administração indireta de todos os entes federados consorciados (MEDAUAR; OLIVEIRA, 2006).

Adquirindo personalidade jurídica de direito privado, será uma "associação civil”, caso em que, apesar de seguir o regime jurídico de direito privado, não poderá deixar de observar inúmeras normas de

\footnotetext{
14 Nesse sentido: Harger (2007, p. 69) e Medauar (2010, p. 227).

15 "Art. $1^{\circ}[\ldots] \S 1^{\circ}$ - O consórcio público constituirá associação pública ou pessoa jurídica de direito privado."
} 
direito público, previstas no $\S 2^{\circ}$ do artigo $6^{\circ}$ da lei: "[...] as normas de direito público no que concerne à realização de licitação, celebração de contratos, prestação de contas e admissão de pessoal, que será regido pela CLT" (MEDAUAR; OLIVEIRA, 2006, p. 74).

Outra característica a ser ressaltada é que a formação dos consórcios públicos exige a subscrição ou posterior ratificação do protocolo de intenções mediante a publicação de lei por cada ente federativo contratante (artigo $5^{\circ}$ ), o que demonstra a necessidade de participação do Legislativo para sua formação.

A Lei $n^{0} 11.107 / 05$ prevê, paralelamente, no lugar de consórcio, duas outras modalidades contratuais a ele relacionadas: os contratos de rateio e os contratos de programa.

O contrato de rateio consiste em um contrato paralelo ao contrato de consórcio e estipula as obrigações financeiras dos entes consorciados. A regra é que as obrigações sejam rateadas em cada exercício financeiro, de acordo com as respectivas dotações orçamentárias.

Já o contrato de programa é utilizado para designar diversas modalidades contratuais. Há dois tipos diferentes: a) o que tem por objeto a prestação de serviços públicos; e b) o que tem por objeto a transferência total ou parcial de encargos, serviços, pessoal e bens necessários à continuidade dos serviços transferidos.

Após a constituição do consórcio público, só serão válidas as obrigações que um ente da Federação assumir para com o outro ou para com o próprio consórcio público, por meio da celebração do contrato de programa (artigo 13).

Tendo em vista as características identificadas a partir dos dispositivos da Lei Federal $n^{\circ} 11.107 / 05$, extrai-se que a distinção marcante entre o convênio e o consórcio reside na intensidade, na complexidade e na estabilidade do vínculo formado por esse último instituto.

Em primeiro lugar, porque, nos termos do artigo $6^{\circ}$, o consórcio público, ao contrário do convênio constitui um ente com personalidade 
jurídica de direito público ou privado, a quem é permitido praticar diversos atos inerentes a uma pessoa administrativa, tais como celebrar contratos, convênios e acordos, outorgar permissões e concessões de serviço público, cobrar tarifas e preços públicos, entre outros (vide artigo $2^{\circ}$, Lei $\left.n^{\circ} 11.107 / 05\right)^{16}$.

Em segundo lugar, porque, ao contrário do regime de convênios, no qual há ampla liberdade para as entidades, a Lei de Consórcios Públicos, em seu bojo, traz regras específicas para a constituição e composição interna do consórcio. Não bastasse isso, ainda limita, nos seus artigos 11 e 12, a retirada dos entes e/ou a extinção do vínculo à prévia aprovação em assembleia, numa votação da qual participam todos os representantes das pessoas jurídicas consorciadas.

\subsection{As vantagens decorrentes da cooperação entre os entes consorciados: gestão associada}

Como visto, os instrumentos de gestão associada de serviços públicos tem assento constitucional (artigo 241 da Constituição Federal de 1988) e amolda-se ao federalismo de cooperação ${ }^{17}$, também instituído constitucionalmente, tendo como objetivos comuns a todos os entes a garantia de desenvolvimento nacional a erradicação da pobreza e marginalização, a redução das desigualdades sociais e regionais, entre outros elencados no artigo $3^{\circ}$ da Constituição.

16 "Art. $2^{\circ}$ Os objetivos dos consórcios públicos serão determinados pelos entes da Federação que se consorciarem, observados os limites constitucionais. $§ 1^{\circ}$ Para o cumprimento de seus objetivos, o consórcio público poderá: I - firmar convênios, contratos, acordos de qualquer natureza, receber auxílios, contribuições e subvenções sociais ou econômicas de outras entidades e órgãos do governo; II - nos termos do contrato de consórcio de direito público, promover desapropriações e instituir servidões nos termos de declaração de utilidade ou necessidade pública, ou interesse social, realizada pelo Poder Público; e III - ser contratado pela administração direta ou indireta dos entes da Federação consorciados, dispensada a licitação. $\S 2^{\circ}$ Os consórcios públicos poderão emitir documentos de cobrança e exercer atividades de arrecadação de tarifas e outros preços públicos pela prestação de serviços ou pelo uso ou outorga de uso de bens públicos por eles administrados ou, mediante autorização específica, pelo ente da Federação consorciado. § $3^{\circ}$ Os consórcios públicos poderão outorgar concessão, permissão ou autorização de obras ou serviços públicos mediante autorização prevista no contrato de consórcio público, que deverá indicar de forma específica o objeto da concessão, permissão ou autorização e as condições a que deverá atender, observada a legislação de normas gerais em vigor."

17 Para aprofundar, conferir: Baracho (1986) e Bercovici (2003). 
O princípio federativo exige, portanto, a colaboração ou cooperação entre União, estados, municípios e Distrito Federal, para o alcance dos sobreditos objetivos fundamentais da República Federativa Brasileira. Como assinala Berti (1993, p. 207 apud JUSTEN FILHO, 2005, p. 10), quanto ao "[...] 'espírito de cooperação' no federalismo, [...] é necessário para que as administrações funcionem e sejam a expressão de qualquer coisa socialmente verdadeira e não autoritariamente imposta".

A cooperação para a realização do interesse público pode ser tratada abstratamente como indissociável aos valores embutidos nas escolhas políticas, sob a premissa de que, uma vez escolhido o interesse a ser defendido, ele será tido como predominante. Em termos práticos, todavia, o jogo político e de expressão do interesse social não é isento de elementos que venham a enfraquecer os seus níveis de eficiência.

Uma forma de enfraquecimento existe quando, sob a roupagem do interesse público, ocultam-se interesses meramente pessoais ou de determinados grupos prevalentes que acabam por se impor como interesse coletivo, quando, na verdade, tem inspiração e objetivos egoísticos. O controle de fundo das escolhas políticas é tarefa bastante problemática.

Outro entrave à eficiência identifica-se nas falhas de coordenação, ou seja, quando as ações que visam a um fim idêntico, similar ou que possam ser unificados são repetidas, conduzindo à duplicação (ou mais) de gastos.

Atuações cooperativas podem reduzir tais vicissitudes, seja porque a cooperação pode funcionar como um freio aos desvirtuamentos dos interesses socialmente relevantes, quando a conduta do agente passa a considerar a conduta do outro agente como elemento norteador da própria, seja quando a cooperação estabelece parâmetros de comportamento que consertam atos de interesse compartilhado.

Além disso, Axelrod (1984) destaca como fundamentos da cooperação a durabilidade da relação e a possibilidade de recompensas mútuas e recíprocas por meio de um processo de seleção das estratégias mais bem sucedidas. 
As vantagens decorrentes da cooperação entre os entes federados são evidentes, conforme destacadas por Medauar e Oliveira (2006): (a) a racionalização dos recursos financeiros, destinados ao planejamento, programação e execução dos objetivos de interesse comum; (b) a criação de vínculos ou o fortalecimento dos vínculos preexistentes, com a formação ou consolidação de uma identidade regional; (c) a instrumentalização da promoção do desenvolvimento local, regional e nacional; e (d) a conjugação de esforços para atender às necessidades da população, as quais não poderiam ser atendidas de outro modo diante de um quadro de escassez de recursos.

Na gestão associada de serviços públicos, a racionalização do uso dos recursos decorre, sobretudo, da economia de escala e do escopo na prestação dos serviços (compras conjuntas com aumento de poder de barganha, redução de preços e despesas administrativas, compartilhamento de equipamentos e infraestrutura, diversificação dos serviços, entre outros).

Toda realização de negócio produz custos, como demonstra Willianson (1985) ao estudar as instituições econômicas do capitalismo e a economia dos custos de transação. Esses custos incidem na realização do negócio, do contrato e durante o seu cumprimento. Adotando-se o modelo de gestão associada ou consorciada, reduz-se o número de contratações e, como consequência, ficam reduzidos os custos de transação ex ante e ex post atrelados a toda contratação. Da mesma forma, destaca Coase (1960) ao examinar os custos das transações no mercado, as operações envolvidas em uma negociação são, em regra, extremamente custosas.

No momento anterior, os custos estão associados, sobretudo, à elaboração do contrato, cujo conteúdo estabelece as bases do negócio - o que engloba a busca de informações sobre o outro contratante. Já no que se refere ao adimplemento do contrato, os custos estarão relacionados à necessidade ou não da tomadas de medidas coercitivas em relação ao contratado, ou, ainda, à eventualidade de se ter por necessária a realização de alguma modificação no conteúdo contratual. 
Agestão associada de serviços públicos permite, em tese, minimizar os custos de transação, devido à redução do número de contratos a partir da prestação do serviço de forma consorciada. Considere-se, por exemplo, a necessidade de um consórcio público delegar à iniciativa privada o serviço de coleta e transporte de resíduos sólidos para o atendimento de 20 municípios integrantes de uma região metropolitana. Nesse caso, seria necessário firmar um contrato de concessão, após a efetivação de licitação. Se tais municípios não fossem integrantes do consórcio público, seriam necessários 20 contratos de concessão, precedidos de 20 licitações públicas, numa clara multiplicação de custos.

Da lição de Coase (1960), pode-se partir para um paralelo entre a possibilidade de redução de custos e o caso examinado (por meio da gestão associada para a prestação de um serviço público) e a lógica de redução de custos a partir de uma forma alternativa de organização econômica, qual seja, a firma (firm), em que as barganhas individuais são eliminadas e substituídas por uma decisão administrativa centralizada.

Conforme apontado, outros evidentes benefícios da cooperação são o fortalecimento político entre os entes federados e o aumento da interação entre eles. Através da conjugação de esforços, é possível atender às necessidades locais ou regionais e promover o desenvolvimento de regiões mais carentes, com direcionamento de recursos financeiros e incentivos fiscais, especialmente no âmbito da prestação de serviços públicos de saneamento básico, o que será examinado nos tópicos seguintes.

Diante das características do regime jurídico do consórcio público, esse instituto parece ser o mais adequado para a implementação de planos integrados de desenvolvimento e prestação compartilhada de serviços públicos, seja por garantir maior segurança jurídica aos entes federados, facilitando a obtenção de financiamentos e viabilizando realização de empreendimentos e programas sociais de longo prazo, seja por permitir que os entes federados coloquem em prática ações conjuntas para a execução dos planos e projetos, tais como contratos, acordos, arrecadação de tarifas e preços públicos, desapropriações etc., 
o que simplifica uma série de procedimentos administrativos e resulta na potencialização dos resultados dos serviços e das ações executadas.

Não obstante, o regime jurídico do convênio propriamente dito ainda permanece como alternativa viável aos vínculos de pequeno vulto e de curto prazo, para os quais o complexo regime de constituição e desenvolvimento de formas associativas apresentar-se-ia oneroso e desnecessário.

Independentemente da utilização de consórcio público ou convênio de cooperação entre os entes federativos, a adoção do sistema de gestão associada é de suma importância para a viabilização de políticas públicas no âmbito dos planos integrados de desenvolvimento. Sobretudo porque possibilita o ajuste entre União, estados, municípios e Distrito Federal, com a conjugação de esforços e por meio do exercício de competência comum/concorrente, para viabilizar investimentos em prol do desenvolvimento econômico, da ampliação e do aperfeiçoamento dos serviços públicos básicos nas regiões mais carentes.

\section{Consórcio público e gerenciamento de resíduos sólidos}

A evolução recente dos serviços de saneamento básico no Brasil desenvolveu-se em três grandes fases, conforme relata Demoliner (2008): a da prestação municipal, até 1970; a da prestação estadual, entre 1970 e 199018; e a posterior a 1990, em que prepondera certo conflito material de competências. Esse último período foi marcado por duas importantes leis gerais sobre a matéria: a Lei de Licitações e

18 Desde a instituição do Plano Nacional de Saneamento - PLANASA, na década de 1970 (regulamentado pela Lei $n^{\circ} 6.528 / 78$ ), os serviços públicos de saneamento básico são, em regra, prestados por empresas públicas estaduais. Na década de 1990, a modelagem tarifária (política de subsídios cruzados não precedida de análise de sustentabilidade) instituída pelo PLANASA entrou em crise, revelando-se ineficientes e deficitárias as companhias estaduais de saneamento básico - CESBs, sobretudo pelos seguintes fatores: situação jurídica irregular dos contratos ditos de concessão firmados sem obediência à legislação nacional; precariedade ou inexistência da regulação da prestação do serviço, especialmente em razão da ausência de controle das tarifas pelo poder concedente; falta de planejamento das CESBs; e ausência de transparência e planejamento das políticas tarifárias. 
Contratos Administrativos (Lei $n^{\circ} 8.666$, de 21 de junho de 1993) e a Lei de Concessões e Permissões de Serviços Públicos (Lei n 8.987, de 13 de fevereiro de 1995).

Não obstante, a superação do conflito material de competências é possível em prol da prevalência da administração pública consensual e da atividade de coordenação administrativa ${ }^{19}$, diante da aprovação da Lei dos Consórcios Públicos (Lei n 11.107, de 6 de abril de 2005) e, mais recentemente, da promulgação da Lei da Política Nacional de Saneamento Básico (Lei $n^{\circ} 11.445$, de 5 de janeiro de 2007) e da Lei da Política Nacional de Resíduos Sólidos (Lei $n^{\circ} 12.305$, de 2 de agosto de 2010). Isso se deve ao fato de que o marco regulatório vigente, para além de enaltecer os benefícios da gestão associada de serviços públicos, prioriza a cooperação técnica e financeira entre os entes federados, alçando-a como princípio e objetivo de tais políticas nacionais.

Como já apontado, é a partir da promulgação da Constituição Federal de 1988 que se começa a repensar a delimitação das competências estaduais e municipais em relação aos serviços públicos de saneamento básico, considerando o conteúdo normativo dos seus artigos $25, \S 1^{\circ}$, e 30 , inciso $\mathrm{V}$, defluindo certo conflito material de competência ${ }^{20}$. Entretanto, devem fazer-se prevalentes as políticas públicas de integração capazes de atender ao interesse público relacionado com o fim de ordenar o pleno desenvolvimento das funções das cidades e o bem-estar de seus habitantes. Como consequência dessa constatação, verifica-se que "[...] a competência da União para instituir diretrizes nacionais para o saneamento básico, mediante lei, insere-se no poder que Ihe foi dato pela Constituição Federal para instituir, também mediante lei, diretrizes para o desenvolvimento urbano" (LOMAR; MUKAI, 2007, p. 5). Diretrizes essas de caráter principiológico

\footnotetext{
19 Ver: Medauar e Oliveira (2006, p.30 e ss).

20 O artigo $25, \S 1^{\circ}$, prescreve: "São reservadas aos Estados as competências que não Ihe sejam vedadas por esta Constituição". Já o Art. 30, V, estabelece que entre as competências municipais está: "organizar e prestar, diretamente ou sob regime de concessão ou permissão, os serviços públicos de interesse local, incluído o de transporte coletivo, que tem caráter essencial.”
} 
e que devem ser seguidas pelos municípios, conforme estabelece o artigo 182 da Constituição ${ }^{21}$ e os termos do artigo $2^{\circ}$ da Lei $11.445 / 07^{22}$ e do artigo $7^{\circ}$ da Lei $12.305 / 10 .{ }^{23}$

No que se refere ao gerenciamento de resíduos sólidos, estudos técnicos produzidos por entidades especializadas em planejamento urbano e saneamento básico vêm apresentando importantes recomendações para implantação de consórcios públicos intermunicipais direcionados à execução daqueles serviços, bem como as vantagens decorrentes desse modelo, notadamente para a destinação de resíduos sólidos urbanos.

Cita-se, nesse sentido, um trabalho referencial publicado em 2007 pela Superintendência de Desenvolvimento de Recursos Hídricos e Saneamento Ambiental do Estado do Paraná (SUDERHSA, 2007), atual Instituto das Águas do Estado do Paraná, intitulado como "Termo de Referência para a Implantação de Consórcios Intermunicipais para Destinação Final de Resíduos Sólidos Urbanos no Estado do Paraná”, em que se destacam "pontos importantes a considerar no planejamento da implantação de consórcios intermunicipais", dentre os quais:

21 "Art. 182: A política de desenvolvimento urbano, executada pelo Poder Público municipal, conforme diretrizes gerais fixadas em lei, tem por objetivo ordenar o pleno desenvolvimento das funções sociais da cidade e garantir o bem-estar de seus habitantes."

22 Esse dispositivo legal estabelece como princípios fundamentais dos serviços públicos de saneamento: a) universalização do acesso; b) integralidade em termos de acesso popular e eficácia das ações; c) adequação à saúde pública e proteção ao meio ambiente; d) disponibilidade geral dos serviços de drenagem e manejo das águas pluviais como mecanismo de promoção da saúde, da segurança e do interesse público; e) consideração das peculiaridades locais e regionais; f) eficiência e sustentabilidade econômica; g) adequação tecnológica permeada pela capacidade contributiva dos usuários e a progressividade das ações; h) transparência; i) controle social; j) segurança, qualidade e regularidade; k) integração das infraestruturas e serviços.

23 O referido dispositivo legal lista os objetivos da Política Nacional de Resíduos Sólidos, dentre os quais: a gestão integrada de resíduos sólidos; a articulação entre as diferentes esferas do poder público, e destas com o setor empresarial, com vistas à cooperação técnica e financeira para a gestão integrada de resíduos sólidos; a regularidade, continuidade, funcionalidade e universalização da prestação dos serviços públicos de limpeza urbana e de manejo de resíduos sólidos, com adoção de mecanismos gerenciais e econômicos que assegurem a recuperação dos custos dos serviços prestados, como forma de garantir sua sustentabilidade operacional e financeira, observada a Lei $n^{\circ} 11.445$, de 2007. 
I. A centralização da destinação final dos resíduos sólidos urbanos para um aterro sanitário intermunicipal colabora para a redução do numero de áreas usadas como aterros e de possíveis focos de contaminação ambiental;

II. Além disso, a centralização da destinação final dos resíduos sólidos urbanos possibilita a geração de ganhos de escala operacional, os quais se aconselha que sejam suficientes para permitir remunerar adequadamente a profissionalização da operação do aterro e, ao mesmo tempo, oferecer uma alternativa aos municípios de destinação final dos resíduos sólidos urbanos que seja economicamente viável ofereça mais recursos para garantir a proteção ambiental.

Assim, o estudo em referência conclui que um aterro sanitário intermunicipal, justamente em razão da maior infraestrutura disponível e maior população atendida, apresenta condições mais favoráveis à viabilização de uma gestão operacional profissional e especializada, por meio da terceirização (concessão) ou termo de cooperação com gestão compartilhada para empresas públicas, mistas ou privadas. Em suma, o objetivo da implantação de um aterro sanitário intermunicipal é a maximização dos benefícios ambientais, econômicos e sociais, decorrentes da gestão integrada do serviço público.

\subsection{Política Nacional de Saneamento Básico}

A prestação de serviços públicos de saneamento básico está inevitavelmente atrelada ao direito a condições de vida digna de todo o cidadão, portanto, o seu tratamento jurídico depende do reconhecimento da relevância dessa temática no Estado brasileiro, do vínculo indissociável entre saneamento básico e direitos fundamentais e do dever de atuação do Estado na promoção dos direitos fundamentais (artigo $1^{\circ}$, inciso III; artigo $3^{\circ}$, incisos III e IV, da Constituição Federal).

Se a Constituição Federal de 1988 está nitidamente voltada à questão social, esta se encontrará materializada pela observância de vários preceitos, dentre os quais, o da adequada prestação dos serviços 
públicos (artigos $6^{\circ}, \S 1^{\circ}$, da Lei $\left.8.987 / 95\right)$. No caso específico dos serviços públicos de saneamento básico, devem ser observados os princípios fundamentais previstos no artigo $2^{\circ}$ da Lei $11.445 / 07$.

Porém, a realidade é que a maioria das cidades brasileiras apresenta serviços de saneamento básico precários ou ineficazes, quando existentes. O crescimento demográfico acelerado pelos diversos fatores históricos e políticos agravou a situação desse setor. Foi com o fenômeno urbanístico da conurbação que se criaram as regiões metropolitanas, nas quais condições econômicas, sociais, culturais e de infraestrutura dos municípios se confundem, exsurgindo interesses comuns entre vários municípios agrupados ou integrantes da região metropolitana

Nesse cenário, os consórcios públicos e os convênios de cooperação são os instrumentos de realização da gestão associada expressamente previstos na Lei de Saneamento Básico (Lei $n^{\circ}$ 11.445/2007), para prestação regionalizada de serviços públicos de saneamento (artigos 13 e 16) e de atividades de regulação e fiscalização (artigo 15) ${ }^{24}$.

O "[...] estímulo à implementação de infra-estruturas e serviços comuns a Municípios, mediante mecanismos de cooperação entre entes federados" trata-se, em verdade, de uma das diretrizes da política de saneamento básico, conforme preceitua a norma contida no artigo 48, inciso $\mathrm{XI}$, da lei em referência.

Além de todas as vantagens decorrentes da cooperação e dos consórcios públicos, a Política Nacional de Saneamento Básico abarca, em seu artigo 31, a possibilidade de adoção de subsídios diretos ou cruzados na gestão integrada de serviços públicos, quando necessários para o atendimento de usuários ou localidades de baixa renda. Acerca dessa solução econômica, propiciada quando a gestão do serviço é

\footnotetext{
24 "Os instrumentos de gestão do serviço público de saneamento não são um fim em si mesmo. Prestam-se à concretização dos princípios fundamentais que norteiam a prestação do serviço." (FORTINI; ROCHA, 2009, p. 154-155).
} 
associada, Justen Filho (2005, p. 30) observa que o chamado subsídio cruzado "[...] se produz por meio da integração do Município carente numa estrutura de prestação de serviços mais abrangente", "transferindo-se os resultados econômicos satisfatórios obtidos em certa região para os usuários de áreas mais carentes".

Tais instrumentos se mostram ainda mais indispensáveis quando trazidas à tona as recomendações do Ministério das Cidades (BRASIL, 2005), pois a implementação de uma política municipal de saneamento não requer apenas a integração dos serviços próprios do saneamento básico entre si (abastecimento de água, esgotamento sanitário, manejo de águas e gestão de resíduos sólidos), mas também com as demais políticas públicas, notadamente, as de saúde, meio ambiente, recursos hídricos, desenvolvimento urbano e rural, habilitação e desenvolvimento regional.

\subsection{Política Nacional de Resíduos Sólidos}

No que concerne às atividades relacionadas ao gerenciamento de resíduos sólidos, ou seja, atividades de saneamento básico atinentes à limpeza urbana e ao manejo de resíduos sólidos, pode-se dizer que a Lei Federal $n^{\circ} 12.305$, de 2 de agosto de 2010, institui seu marco regulatório, sem olvidar-se da Lei Federal $n^{\circ} 11.445$, de 5 de janeiro de 2007, que estabelece as diretrizes nacionais para o saneamento básico.

No regime jurídico de Direito Ambiental, incide em toda sua amplitude o princípio da cooperação que envolve a ideia de atuação da sociedade em conjunto com o Estado na escolha de prioridades ambientais, para formulação e execução de políticas públicas de escopo ambiental (artigo $6^{\circ}$ da Política Nacional de Resíduos Sólidos). Essa concepção em nada conflita com os valores atrelados à cooperação entre entes federados para fins de gestão associada de serviços públicos, anteriormente examinados.

Nota-se também que, na seara ambiental, amplia-se a carga axiológica de cooperação e gestão associada, a qual, ao lado da busca pelo gerenciamento ambientalmente adequado dos resíduos, passa a 
ser uma diretriz geral da Política Nacional de Resíduos Sólidos, nos termos do caput do seu art. $4^{\circ}$.

São diversos os dispositivos da Política Nacional de Resíduos Sólidos que fazem alusão à cooperação, à gestão integrada, a soluções consorciadas e compartilhadas e ao consórcio público:

- artigo $7^{\circ}$, inciso VIII (objetivos da Política Nacional de Resíduos Sólidos): "[...] articulação entre as diferentes esferas do poder público, e destas com o setor empresarial, com vistas à cooperação técnica e financeira para a gestão integrada de resíduos sólidos";

- artigo $8^{\circ}$, inciso VI (instrumentos da Política Nacional de Resíduos Sólidos): "[...] a cooperação técnica e financeira entre os setores público e privado para o desenvolvimento de pesquisas de novos produtos, métodos, processos e tecnologias de gestão, reciclagem, reutilização, tratamento de resíduos e disposição final ambientalmente adequada de rejeitos";

- artigo 15, incisos VIII e IX (conteúdo mínimo da Política Nacional de Resíduos Sólidos): "[...] medidas para incentivar e viabilizar a gestão regionalizada dos resíduos sólidos" e "[...] diretrizes para o planejamento e demais atividades de gestão de resíduos sólidos das regiões integradas de desenvolvimento instituídas por lei complementar, bem como para as áreas de especial interesse turístico";

- artigo 16, incisos VIII e IX (conteúdo mínimo da Política Estadual de Resíduos Sólidos): "[...] medidas para incentivar e viabilizar a gestão consorciada ou compartilhada dos resíduos sólidos" e "[...] diretrizes para o planejamento e demais atividades de gestão de resíduos sólidos de regiões metropolitanas, aglomerações urbanas e microrregiões";

- artigo 19, inciso III (conteúdo mínimo do Plano Municipal de Gestão Integrada de Resíduos Sólidos): "[...] identificação das possibilidades de implantação de soluções consorciadas ou compartilhadas com outros Municípios, considerando, nos critérios de economia de escala, a proximidade dos locais estabelecidos e as formas de prevenção dos riscos ambientais". 
Para especialistas do Instituto Brasileiro de Administração Pública (IBAM), "[...] gerenciar o lixo de forma integrada demanda trabalhar integralmente os aspectos sociais com o planejamento das ações técnicas e operacionais do sistema de limpeza urbana". (INSTITUTO BRASILEIRO DE ADMINISTRAÇÃO MUNICIPAL, 2001, online)

A elaboração de planos de resíduos sólidos, a partir de 2 de agosto de 2014, passa a ser condição para que estados, municípios e Distrito Federal tenham acesso a recursos federais (confira os artigos 16, 18 e 55 da Política Nacional de Resíduos Sólidos). Ademais, serão priorizados recursos da União aos entes que optarem por soluções consorciadas (vide artigo $16, \S 1^{\circ}$, e artigo $18, \S 1^{\circ}$, inciso I da Política Nacional de Resíduos Sólidos).

O artigo 45 da Lei $n^{\circ}$ 12.305/10 estabelece que terão prioridade na obtenção de incentivos federais os consórcios públicos legalmente constituídos com o objetivo de gestão associada de serviços públicos que envolvam resíduos sólidos. Há, portanto, tratamento jurídico diferenciado dos consórcios públicos no âmbito da política de fomentos e incentivos creditícios, o que se reforça pela norma preceituada no artigo 42, inciso IV, da Política Nacional de Resíduos Sólidos.

No documento intitulado "Manual de Gerenciamento Integrado de Resíduos Sólidos", elaborado e coordenado por técnicos do IBAM, esclarece-se como o consórcio público se insere e se faz compatível com os serviços relacionados ao gerenciamento de resíduos sólidos, citando um exemplo exitoso de implantação desse instrumento:

Como a gestão de resíduos é uma atividade essencialmente municipal $e$ as atividades que a compõem se restringem ao território do Município, não são muitos comuns no Brasil as soluções consorciadas, a não ser quando se trata de destinação final em aterros. Municípios com áreas mais adequadas para instalação dessas unidades operacionais às vezes se consorciam com cidades vizinhas para receber os seus resíduos, negociando algumas vantagens por serem hospedeiros, tais como isenção do custo de vazamento ou alguma compensação urbanística, custeada pelos outros consorciados. 
Um dos exemplos mais bem-sucedidos no campo do consórcio é aquele formado pelos municípios de Jundiaí, Campo Limpo Paulista, Cajamar, Louveira, Várzea Paulista e Vinhedo, no Estado de São Paulo, para operar o aterro sanitário de Várzea Paulista.

A partir do estudo em referência, observa-se que o gerenciamento integrado de resíduos sólidos pode não se limitar à formação de consórcios ou convênios entre entes federados. Outros aspectos, além dos operacionais, podem ser destacados da concepção do gerenciamento integrado, como a importância das questões econômicas e sociais relacionadas à limpeza urbana, bem como as políticas públicas - locais ou não - que possam estar associadas ao gerenciamento do lixo, na área de saúde, trabalho e renda, planejamento urbano, entre outras.

\section{Conclusão}

Conclui-se, a partir das considerações postas, que a gestão associada de serviços públicos é um meio de atuação conjunta que União, estados, municípios e Distrito Federal possuem para atender aos anseios da coletividade, através da prestação de um serviço público de modo amplo e eficiente. Os modelos de gestão associada, consórcios públicos e convênios de cooperação revelam-se de fundamental importância na flexibilização de competências, levando-se em conta a problemática ecológica, global e complexa que exige uma regulação do conjunto, para além dos limites das autoridades locais (OST, 1995).

Tanto a Lei de Saneamento Básico como a Política Nacional de Resíduos Sólidos consagram o princípio constitucional da eficiência, introduzido no caput do artigo 37, pela Emenda Constitucional $n^{\circ} 19$, de 1998. Na Lei n 11.445/2007, tal princípio é adjetivado como fundamental ao lado do princípio da viabilidade econômica (artigo $2^{\circ}$, inciso VII). Já na Lei $n^{\circ} 12.305 / 2010$, ao princípio da eficiência foi acrescida a carga axiológica ambiental, apresentando-se repaginado como "ecoeficiência" (artigo $6^{\circ}$, inciso V). 
A expressa ponderação do princípio da eficiência no aparato legislativo disciplinador da atividade econômica de gerenciamento de resíduos sólidos evidencia a preocupação do legislador em alcançar os resultados almejados pela prestação de tais serviços essenciais, quais sejam, os fins sociais decorrentes do desenvolvimento sustentável.

A partir da constatação de que a prestação dos serviços de gerenciamento de resíduos sólidos de forma consorciada ou compartilhada se dá de forma mais econômica e melhor em comparação à prestação dos serviços por meio de um único ente federado, está plenamente atendido o princípio da eficiência, consagrado no caput do artigo 37 da Constituição Federal, pois eficiência significa realizar mais e melhor com menos, ou seja, prover os serviços públicos necessários de maneira satisfatória e com qualidade, mediante o mínimo necessário de suporte financeiro (BACELLAR FILHO, 2008).

A redução dos custos associados aos contratos, especialmente diante da possibilidade de redução de seu número por meio de uma operação conjunta e otimizada, é mais um fator de estímulo à gestão compartilhada dos serviços públicos.

Não demanda grande esforço teórico concluir que a eficiência é incrementada em todos os seus aspectos quando se integram, por exemplo, dois sistemas municipais de saneamento básico contidos em uma mesma urbe, quer pela "eficiência operativa" (consecução de um bom planejamento e uma boa formulação de metas), quer pela "eficiência adaptativa" (boa capacidade de reformulação de metas), quer pela "eficiência técnica" (relação entre os recursos empregados e os resultados), quer, ainda, pela "eficiência consignativa" (distribuição ótima dos recursos disponíveis). Ademais, atende ao que se convencionou denominar de "eficiência moral", aquela decorrente de uma razão ética, na qual se busca uma eficácia temporal condicionada por valores típicos da boa administração, ou seja, em que se atende aos interesses concretos do cidadão, em detrimento de interpretações formalistas distantes da realidade (GABARDO, 2001). 
Por outro lado, a associação dos entes públicos também funciona como elemento facilitador da implementação de políticas de médio e longo prazo, gerando maior estabilidade na formalização de ações relacionadas à prestação de serviços públicos associados a políticas econômicas que possam promover o aprimoramento da forma de vida em sociedade. A cooperação pode, inclusive, funcionar como fator de garantia de persecução de objetivos socialmente relevantes diante do engajamento recíproco que dela decorre.

Os consórcios públicos, instrumentos de gestão associada de serviços públicos de esteio constitucional (artigo 241 da Constituição Federal), podem ser utilizados para que se alcance eficiência nas atividades de gerenciamento de resíduos sólidos, de forma a se obter a universalização desses serviços. E como evidência positiva resultante da atividade econômica de gerenciamento de resíduos sólidos eficiente, coloca-se o desenvolvimento sustentável, pois uma economia em desenvolvimento sustentável tem maior potencial de adaptação e aperfeiçoamento em conhecimento, organização e eficiência técnica (DALY, 2004).

\section{Referências}

ASCARELLI, Tullio. Problemas das sociedades anônimas e direito comparado. 3. ed. São Paulo: Saraiva, 2000.

AXELROD, R. The evolution of cooperation. New York: Basic Books, 1984.

BACELLAR FILHO, Romeu Felipe. Direito administrativo. 4. ed. São Paulo: Saraiva, 2008.

BARACHO, José Alfredo de Oliveira. Teoria geral do federalismo. Rio de Janeiro: Forense, 1986.

BERCOVICI, Gilberto. Desigualdades regionais, estado e constituição. São Paulo: Max Limonad, 2003. 
BRASIL. Ministério das Cidades. Mobilidade e política urbana: subsídios para uma gestão integrada. Coordenação de Lia Bergman e Nídia Inês Albesa de Rabi. Rio de Janeiro: IBAM, 2005. Disponível em: <http://www.ibam.org.br/media/arquivos/estudos/mobilidade.pdf>. Acesso em: 29 jun. 2012.

BRASIL. Ministério das Cidades. Sistema nacional de informações sobre saneamento. Diagnóstico do manejo de resíduos sólidos urbanos: 2005. Brasília, DF, 2007.

CARVALHO FILHO, José dos Santos. Consórcios públicos. Rio de Janeiro: Lumen Juris, 2009.

COASE, Ronald. O problema do custo social. Journal of law and economics, London, v. 3, p. 1-44, out. 1960.

DALY, Herman E. Crescimento sustentável? Não, obrigado. Ambiente \& Sociedade, Campinas, SP, v. 7, n. 2. jul./dez. 2004. Disponível em: <http://www.scielo.br/pdf/asoc/v7n2/24695.pdf>. Acesso em: 9 ago. 2011.

DEMOLINER, Karine Silva. Água e saneamento básico: regimes jurídicos e marcos regulatórios no ordenamento brasileiro. Porto Alegre: Livraria do Advogado, 2008.

DI PIETRO, Maria Sylvia Zanella. Direito administrativo. 19. ed. São Paulo: Atlas, 2006.

FORTINI, Cristiana; ROCHA, Rúsvel Beltrame. Consórcios públicos, contratos de programa e a Lei de Saneamento. In: PICININ, Juliana; FORTINI, Cristiana (Org.). Saneamento básico: estudos e pareceres à luz da Lei n 11.445/2007. Belo Horizonte: Fórum, 2009. p.137-156.

GABARDO, Emerson. Princípio constitucional da eficiência administrativa. São Paulo: Dialética, 2001.

HARGER, Marcelo. Consórcios públicos na Lei $n^{\circ} 11.107 / 05$. Belo Horizonte: Fórum, 2007.

INSTITUTO BRASILEIRO DE ADMINISTRAÇÃO MUNICIPAL. Manual de gerenciamento integrado de resíduos sólidos. 2001. Disponível 
em: <http://www.ibam.org.br/media/arquivos/estudos/manual_girs.pdf>. Acesso em: 29 jun. 2012.

JUSTEN FILHO, Marçal. Parecer sobre a minuta de anteprojeto da Lei da Política Nacional de Saneamento Básico. 2005. Disponível em: <http://www.planalto.gov.br/CCIVIL_03/revista/Rev_72/Pareceres/ saneamento_complementar_MarcalJustenFilho_1.pdf>. Acesso em: 8 ago. 2011.

JUSTEN FILHO, Marçal. Parecer sobre a proposta legislativa de criação de consórcios públicos. 2005. Disponível em: < http://www. direitodoestado.com/revista/REDE-3-JULHO-2005-MAR\%C7AL\%20 JUSTEN\%20FILHO.pdf>. Acesso em: 9 ago. 2011.

LOMAR, Paulo José Villela. Dos princípios fundamentais. In: MUKAI, Toshio (Coord.). Saneamento básico: diretrizes gerais, comentários à Lei 11.445 de 2007. Rio de Janeiro: Lumen Juris, 2007. p. 9-11.

MEDAUAR, Odete. Direito administrativo moderno. São Paulo: Revista dos Tribunais, 2010.

MEDAUAR, Odete; OLIVEIRA, Gustavo Justino de. Consórcios públicos: comentários à Lei 11.107/2005. São Paulo: Revista dos Tribunais, 2006.

MEIRELLES, Hely Lopes. Direito administrativo brasileiro. 7. ed. São Paulo: Revista dos Tribunais, 1979.

OST, François. A natureza à margem da lei: a ecologia à prova do direito. Lisboa: Instituto Piaget, 1995.

PARANÁ. Superintendência de Desenvolvimento de Recursos Hídricos e Saneamento Ambiental. Termo de referência para a implantação de consórcios intermunicipais para destinação final de resíduos sólidos urbanos no Estado do Paraná, 2007. Disponível em: <http:// www.aguasparana.pr.gov.br/arquivos/File/TermoReferencia_Mapa_ consorcios_01-10-07_final2.pdf>. Acesso em: 4 jun. 2012. 
SOUZA, Rodrigo Pagani de. A experiência brasileira nas concessões de saneamento básico. In: SUNDFELD, Carlos Ari (Coord.). Parcerias público-privadas. São Paulo: Malheiros, 2005. p. 326-356.

WILLIAMSON, Oliver E. The economic institutions of capitalism: firms, markets, relational contracting. New York: The Free Press, 1985.

Recebido em: 00/11/13

Aprovado em: 00/12/13 